\title{
DE VOORGENOMEN UITBREIDING VAN WILLEMSTAD OP CURACAO, ORANJESTAD EN SINT NICOLAAS OP ARUBA \\ DOOR
}

\section{DR. JOH. HARTOG}

Reeds geruimen tijd hunkert de benarde Willemstad naar uitbreiding. Van Walbeeck legde zelf den grondslag voor deze stad, toen hij aan de Punt (Punda) een fort bouwde, dat in 1635, een jaar na dat, waarin de Hollanders voet aan wal zetten, werd in gebruik genomen. In $1637 \mathrm{kwam}$ er een voorlooper van het tegenwoordige gouvernementshuis. Na den vrede van Munster werd de ommuurde stad naar stadhouder Willem II genoemd. In 1675, als de haven van Curaçao voor het wereldverkeer wordt opengesteld, is uitbreiding noodig. Dan gaat in 1707 directeur Jacob Beck aan de Overzijde bouwen. Dat is de eerste uitbreiding.

De tweede uitbreiding is het tegenwoordige Julianaplein bij Altena.

In 1756 neemt de West-Indische compagnie zelf een uitbreidingsplan ter hand, dat eerst een eeuw later zijn beslag kreeg.

$\mathrm{Na}$ den vrede van Parijs in 1763, waardoor vele scheepvaartbelemmeringen uit den weg werden geruimd, kwam Curaçao meer in het centrum. De groei van Otrabanda dagteekent uit dien tijd. Twee kerken getuigen hiervan: de Luthersche kerk, die niet meer bestaat, en de St. Annakerk van 1769, die onder het Engelsche bewind haar toren kreeg.

Het keurslijf der stad bleef klemmen, tot in 1861 werd begonnen met het sloopen der wallen. Willemstad werd toen wat het eerst 16 Februari 1918 (Pb. 1918 no. 39 officieel genoemd werd: het geheele stadsdistrict. Historisch is de Willemstad alleen het oude Pundagedeelte.

De vrijheid om de stad uit te breiden werd ongebreideld benut. Wat er leelijk is, is bijna alles terug te brengen tot den tijd 
na 1861. In Punda en Otrabanda zijn nu nog een 60 voorbeelden van achttiende-eeuwsche architectuur te vinden. Enkele fraaie stadsuitbreidingen van na de openlegging in 1861, als de Palmenlaan van De Rouville aan het Molenplein, zijn alweer verdwenen.

Zoo heeft Willemstad zich ontwikkeld tot wat het nu is, nl. enkele groote hoofdwegen, die door een gekrioel van steegjes en straatjes met elkaar verbonden zijn, een wanorde, die vergroot werd, toen als gevolg van de komst van ,de olie" de uitbreiding van de bevolking, het verkeer enz. zoo toenamen, dat er geen maat meer te houden was. Allereerst ontstond de wel geordende, zij het architectonisch niet overal even fraaie Emmastad (het tweede district, voor zoover begrepen in Negropont, Asiento en Valentijn; Proclamatie van 10 Jan. 1929, Pb. no. 3).

In onze dagen kwam het weder tot een uitbreidingsplan, stelselmatig opgezet en bewerkt door den bouwkundigen ingenieur C. M. Bakker. Aruba werd erin betrokken. De hoofdstad Oranjestad (zoo genoemd in 1825) zag zich door de enorme opleving van dat eiland eveneens gesteld voor merkwaardige problemen, en daarnaast had men die van de ,boom-town" Sint Nicolaas (officieele naam van wat de volksmond San Nicolas noemt), dat heelemaal zonder orde uit den grond verrezen was.

Een en ander leidde tot het boek, dat de directeur van Openbare werken, ir. J. Groote, in Maart 1945 gereed had en den gouverneur aanbood. Sedert is het in het licht gegeven. Anders dan met ambtelijke rapporten gewoonlijk het geval is, is dit boek vlot leesbaar, goed gesteld, wel gedocumenteerd en behoorlijk aangekleed.

De kern, voor zoover hier behoorlijk weer te geven, komt hierop neer:

Willemstad. Ontworpen zijn parallelwegen van de ceintuurbaan om het Schottegat. De ceintuurbaan zelf wordt voltooid door een 45 meter hooge brug over de St. Annabaai, die de schakel Parera-Plantersrust vormt. Aan de Pundakant geeft de brug rechtstreeks aansluiting op Scharloo en Pietermaai en via een anderen afgang op den Schottegatweg/Parera. Over het Waaigat komt een andere brug.

Aan de Otrabanda is eveneens een dubbele afgang: de eene via Arubastraat, Klipstraat naar het Brionplein en via een nieuwen weg over het Rif naar Cas Chiquito, terwijl via den Witteweg een afgang naar den Roodeweg beschikbaar komt; de tweede afgang loopt rechtstreeks door naar Welgelegen en geeft daar aansluiting op het nieuwe wegennet, dat men begonnen is aan te leggen. 
Buiten de stadskern komt er uitbreiding van wegen om de Caracasbaai, Mahaai en de streek tot Santa Maria toe.

Oranjestad. Er komt een ceintuurbaan van het Strandhotel om de stad heen over Seroe Blancoe en Socotora door de Rancho naar den zeeweg.

Sint Nicolaas. Twee flinke wegen zijn ontworpen: een dicht bij de bestaande bebouwing en een andere aan de Noordzijde van de geprojecteerde nieuwe wijk. Daartusschen komen nieuwe woonwijken.

$\mathrm{Er}$ is niet gestreefd naar het strakke, vaak dorre rythme van den Amerikaanschen stedenbouw (waartegen al een reactie merkbaar is), maar bovendien is vermeden van de steden doolhoven te maken.

$\mathrm{Al}$ deze nieuwe straten brengen vanzelf vermeerdering van de woningen mee. Daar het jaarlijksche geboorteoverschot ongeveer 1200 is in het gebiedsdeel Curaçao, zijn er per jaar ongeveer 200 tot 250 nieuwe woningen noodig en 10 tot 20 schoollokalen. Over 10 jaar ongeveer zijn er voldoende menschen in Curaçao om de industrieën van arbeidskrachten te voorzien. De bevolkingsaanwas is jaarlijks $141 / 2$ kind op 100 vrouwen tusschen 15 en 45 jaar; in Amsterdam maar 6. Met het oog hierop acht ir. Groote het noodig op den duur een deel der bevolking in dorpsgemeenschappen onder te brengen, een plan, dat al meer dan een eeuw geleden door den emancipator van Curaçao monseigneur Niewindt is voorgesteld.

De nieuwe straten zullen verlichting in het overladen verkeer brengen; uit ir. Groote 's rapport leert men, met cijfers toegelicht, dat het autoverkeer op den berg Altena bijvoorbeeld grooter is dan op het Koningsplein of het Rokin te Amsterdam, dat de drukke Overtoom een rustige verkeersweg is, vergeleken bij den Rooden weg op Otrabanda, de smalle weg naar Santa Rosa meer auto's verzet dan de Willemsparkweg en Scharloo, de wegen naar Caracasbaai en zelfs die in het derde district drukker zijn dan de dubbele Admiraal De Ruyter-weg in 's Rijks hoofdstad; over de rustige gedeelten van den Schottegatweg rijden meer auto's dan op de uitvalwegen van Amsterdam naar het Gooi of Haarlem.

De uitvoering van het uitbreidingsplan zal voor Curaçao tien en voor Aruba, waar meer gebeuren moet, ongeveer 20 jaar vergen.

Bij Parera komt 600 meter kaderuimte, waaromheen een speciale verkeersweg komt. Oranjestad krijgt een verdubbeling van haar kaderuimte. 
In de kantoorruimte in Oranjestad is voorzien kunnen worden door de ontruiming der militaire gebouwen. Dit wordt een nieuwe wijk langs de zee, waarin schouwburg, ontvangers- en douanekantoor, passangrahan, postkantoor en magazijnen. Hoe hetzelfde vraagstuk te Willemstad moet worden opgelost is niet duidelijk. De vorige Staten hebben het desbetreffende voortreffelijke plan, in dit rapport voorkomende, reeds afgestemd. Misschien toonen de tegenwoordige Staten op dit punt meer inzicht.

Langs het Waaigat komt een nieuwe weg, toegang gevende tot de brug. De bocht in de De Ruyter-kade langs het Waaigat en bij de palmen voorbij de Theaterstraat wordt aangeplempt. Het Waaigat zelf wil het uitbreidingsplan behouden met het oog op het stadsschoon, en dat terecht. Vóór de De Ruyter-kade komt nu een vlakte, begrensd door den zoo juist genoemden nieuwen weg. Op die vlakte komen zoowel de markthal als het groote Bestuurskantoor en het Post- en Telegraafkantoor. Zooals men weet, zijn nu de verschillende bestuursdiensten verspreid, wat tot veel tijdverlies leidt. Het postkantoor, nu benard gehuisvest (en toch nog het ruimst) binnen $800 \mathrm{~m}^{2}$., krijgt $50 \%$ meer ruimte; dit zou nù al te weinig zijn. Alles bij elkaar beschikken de gouvernementskantoren nu zonder het postkantoor over ongeveer $3000 \mathrm{~m}^{2}$. en het ligt in de bedoeling, dat dit $5000 \mathrm{~m}^{2}$ zal worden.

Het tegenwoordige postkantoor en de gouvernementssecretarie worden verbouwd voor den Eilandraad en de Staten, zoodat het fort Amsterdam een soort Binnenhof wordt, waardig tevens voor officieele ontvangsten. De tegenwoordige Statenzaal wordt ter beschikking gesteld van de voor de rechtspraak noodige ruimten.

Het afbreken van de heele Punda om daar een gebouw op te richten met de noodige parkeerruimte zou te duur zijn en niet voldoende parkeergelegenheid bieden. Reeds in 1944 waren er 3657 auto's op Curaçao. Op Aruba is dat getal 2058, maar per 1000 inwoners levert dat een hooger cijfer op dan op Curaçao.

Ir. Groote acht voor de verbinding Punda-Otrabanda een tunnel de meest afdoende oplossing, doch ook de meest kostbare. De bouwkosten worden geschat op 10.000.000 gulden, en de terugkeerende kosten van ventilatie, bewaking, brandweer, moeten ook in rekening gebracht worden. Deze laatste kosten zijn hooger dan die van het verlies aan benzine bij omrijden in geval er een brug komt. Van deze laatste worden de kosten op 4 millioen geschat, die in 30 jaar zouden kunnen worden afgeschreven. 
De minimumschade van het wachten voor de geopende schipbrug schat de heer Groote voor particulieren op 3 ton 's jaars. Hiermee zijn de hoofdlijnen van het 100 bladzijden tellende rapport weergegeven. Niet met alles behoeft men het eens te zijn om de woorden van den steller te kunnen onderschrijven: „,Voor de toekomst bouwen wij, voor haar welzijn trachten wij stad en land van de toekomst een betere gedaante te geven, een gedaante, welke haar geestelijke zoowel als haar economische gesteldheid dient". 